\title{
Approximation Analysis for a Common Fixed Point of Finite Family of Mappings Which Are Asymptotically $k$-Strict Pseudocontractive in the Intermediate Sense
}

\author{
H. Zegeye ${ }^{1}$ and N. Shahzad ${ }^{2}$ \\ ${ }^{1}$ Department of Mathematics, University of Botswana, Private Bag 00704, Gaborone, Botswana \\ ${ }^{2}$ Department of Mathematics, King Abdulaziz University, P.O. Box 80203, Jeddah 21589, Saudi Arabia
}

Correspondence should be addressed to N. Shahzad; nshahzad@kau.edu.sa

Received 16 February 2013; Accepted 18 April 2013

Academic Editor: Luigi Muglia

Copyright (c) 2013 H. Zegeye and N. Shahzad. This is an open access article distributed under the Creative Commons Attribution License, which permits unrestricted use, distribution, and reproduction in any medium, provided the original work is properly cited.

We introduce an iterative process which converges strongly to a common fixed point of a finite family of uniformly continuous asymptotically $k_{i}$-strict pseudocontractive mappings in the intermediate sense for $i=1,2, \ldots, N$. The projection of $x_{0}$ onto the intersection of closed convex sets $C_{n}$ and $Q_{n}$ for each $n \geq 1$ is not required. Moreover, the restriction that the interior of common fixed points is nonempty is not required. Our theorems improve and unify most of the results that have been proved for this important class of nonlinear mappings.

\section{Introduction and Preliminaries}

Let $C$ be a nonempty subset of a real Hilbert space $H$. A mapping $T: C \rightarrow H$ is called Lipschitzian if there exists $L>0$ such that $\|T x-T y\| \leq L\|x-y\|$, for all $x, y \in C$. If $L=1$, then $T$ is called nonexpansive, and if $L \in[0,1)$, $T$ is called contraction. $T$ is called uniformly L-Lipschitzian if there exists $L>0$ such that $\left\|T^{n} x-T^{n} y\right\| \leq L \| x-$ $y \|$, for all $x, y \in C$ and all $n \geq 1$. Clearly, every contraction mapping is nonexpansive and every nonexpansive mapping is uniformly $L$-Lipschitzian with $L=1$ and hence Lipschitzian.

A mapping $T: C \rightarrow H$ is said to be asymptotically nonexpansive if there exists a sequence $\left\{\gamma_{n}\right\} \subset[0, \infty)$ with $\gamma_{n} \rightarrow 0$ such that $\left\|T^{n} x-T^{n} y\right\| \leq\left(1+\gamma_{n}\right)\|x-y\|$ for all integers $n \geq 1$ and all $x, y \in C$.T is said to be asymptotically nonexpansive in the intermediate sense if there exist sequences $\left\{\gamma_{n}\right\},\left\{c_{n}\right\} \subset[0, \infty)$ with $\gamma_{n} \rightarrow 0, c_{n} \rightarrow 0$ such that $\left\|T^{n} x-T^{n} y\right\| \leq\left(1+\gamma_{n}\right)\|x-y\|+c_{n}$ for all integers $n \geq 1$ and all $x, y \in C$.
A mapping $T: C \rightarrow H$ is said to be asymptotically $k$ strict pseudocontractive if there exist a constant $k \in[0,1)$ and a sequence $\left\{\gamma_{n}\right\} \subset[0, \infty)$ with $\gamma_{n} \rightarrow 0$, as $n \rightarrow \infty$, such that

$$
\begin{aligned}
\| T^{n} x- & T^{n} y \|^{2} \\
\leq & \left(1+\gamma_{n}\right)\|x-y\|^{2} \\
& +k\left\|\left(I-T^{n}\right) x-\left(I-T^{n}\right) y\right\|^{2}, \quad \forall x, y \in C .
\end{aligned}
$$

The class of asymptotically $k$-strict pseudocontractive mappings which includes the class of asymptotically nonexpansive, and hence the class of nonexpansive mappings was introduced by Liu [1] in 1996 (see, also [2]). Kim and Xu [3] proved that the fixed point set of asymptotically $k$-strict pseudocontractions is closed and convex. Recall that a fixed point of a map $T: C \rightarrow H$ is a set $\{x \in C: T x=x\}$, and it is denoted by $F(T)$. In addition, it is noted in [3] that every asymptotically $k$-strict pseudocontractive mapping with sequence $\left\{\gamma_{n}\right\}$ is a uniformly $L$-Lipschitzian mapping with $L:=\sup \left\{\left(k+\sqrt{1+(1-k) \gamma_{n}}\right) /(1-k): n \in \mathbb{N}\right\}$. 
A mapping $T$ is said to be an asymptotically $k$-strict pseudocontractive in the intermediate sense if

$$
\begin{aligned}
\limsup _{n \rightarrow \infty} \sup _{x, y \in C}\left(\left\|T^{n} x-T^{n} y\right\|^{2}-\left(1+\gamma_{n}\right)\|x-y\|^{2}\right. \\
\left.-k\left\|\left(I-T^{n}\right) x-\left(I-T^{n}\right) y\right\|\right) \leq 0,
\end{aligned}
$$

where $k \in[0,1)$ and $\left\{\gamma_{n}\right\} \subset[0, \infty)$ such that $\gamma_{n} \rightarrow 0$, as $n \rightarrow \infty$. If we put

$$
\begin{gathered}
c_{n}:=\max \left\{0, \sup _{x, y \in C}\left(\left\|T^{n} x-T^{n} y\right\|^{2}-\left(1+\gamma_{n}\right)\|x-y\|^{2}\right.\right. \\
\left.\left.-k\left\|\left(I-T^{n}\right) x-\left(I-T^{n}\right) y\right\|^{2}\right)\right\} .
\end{gathered}
$$

It follows that $c_{n} \rightarrow 0$, as $n \rightarrow \infty$, and (2) is reduced to the following:

$$
\begin{aligned}
\| T^{n} x- & T^{n} y \|^{2} \\
\leq & \left(1+\gamma_{n}\right)\|x-y\|^{2} \\
& +k\left\|\left(I-T^{n}\right) x-\left(I-T^{n}\right) y\right\|^{2}+c_{n}, \quad \forall x, y \in C .
\end{aligned}
$$

We note that the class of asymptotically $k$-strict pseudocontractive mappings is properly contained in a class of asymptotically $k$-strict pseudocontractive mapping in the intermediate sense (see examples in [4]). The class of asymptotically $k$-strict pseudocontractive mappings in the intermediate sense was introduced by Sahu et al. [4]. They obtained a weak convergence theorem of modified Mann iterative processes for these class of mappings. In [4], Sahu et al. established the following classical result.

Theorem SXY1 (see [4]). Let $H$ be a real Hilbert space, and let $C \subset \mathrm{C}$ be a nonempty closed and convex set. Let $T$ be a uniformly continuous and asymptotically $k$-strict pseudocontractive mapping in the intermediate sense with sequences $\left\{\gamma_{n}\right\}$ and $\left\{c_{n}\right\}$ such that $F(T)$ is nonempty and $\sum_{n=1}^{n} \gamma_{n}<\infty$. Assume that $\left\{\alpha_{n}\right\}$ is a sequence in $(0,1)$ such that $0<\delta \leq \alpha_{n} \leq 1-k-\delta<1$ and $\sum_{n=1}^{n} \alpha_{n} c_{n}<\infty$. Let $\left\{x_{n}\right\}$ be a sequence defined by $x_{1}=x \in C$ and

$$
x_{n+1}=\left(1-\alpha_{n}\right) x_{n}+\alpha_{n} T^{n} x_{n}, \quad n \geq 1 .
$$

Then, $\left\{x_{n}\right\}$ converges weakly to a fixed point of T.

But it is worth mentioning that the convergence obtained is a weak convergence. Furthermore, we observe from the proof of Theorem SXY1 that if, in addition, $C$ or $T$ has some compactness assumption, we obtain that the sequence $\left\{x_{n}\right\}$ given by (5) converges strongly to a fixed point of $T$.

Attempts to modify the Mann iteration method (5) so that strong convergence is guaranteed, without compactness assumption on $C$ or $T$, have recently been made. Sahu et al. [4] established the following hybrid Mann algorithm for approximating fixed points of asymptotically $k$-strict pseudocontractive mappings in the intermediate sense.
Theorem SXY2 (see [4]). Let $H$ be a real Hilbert space, and let $C \subset \mathrm{C}$ be a nonempty, closed, and convex set. Let $\mathrm{T}$ be a uniformly continuous asymptotically $k$-strict pseudocontractive mapping in the intermediate sense with sequences $\left\{\gamma_{n}\right\}$ and $\left\{c_{n}\right\}$ such that $F(T)$ is nonempty and bounded. Assume that $\left\{\alpha_{n}\right\}$ is a sequence in $[0,1]$ such that $0<\delta \leq \alpha_{n} \leq 1-k$, for all $n \in N$. Let $\left\{x_{n}\right\}$ be a sequence in $C$ defined by $u=x_{1} \in C$ and

$$
\begin{gathered}
y_{n}=\left(1-\alpha_{n}\right) x_{n}+\alpha_{n} T^{n} x_{n}, \quad n \geq 1, \\
C_{n}=\left\{z \in C:\left\|y_{n}-z\right\|^{2} \leq\left\|x_{n}-z\right\|^{2}+\theta_{n}\right\}, \\
Q_{n}=\left\{z \in C:\left\langle x_{n}-z, u-x_{n}\right\rangle \geq 0\right\}, \\
x_{n+1}=P_{C_{n} \cap Q_{n}}(u), \quad n \geq 1,
\end{gathered}
$$

where $\theta_{n}=c_{n}+\gamma_{n} \delta_{n}$ and $\delta_{n}=\sup \left\{\left\|x_{n}-z\right\|: z \in F(T)\right\}<\infty$. Then, $\left\{x_{n}\right\}$ converges strongly to $P_{F(T)}(u)$.

Recently, Hu and Cai [5] studied the strong convergence of the modified Mann iteration process (5) for a finite family of asymptotically $k$-strict pseudocontractive mappings in the intermediate sense. More precisely, they obtained the following theorem.

Theorem HC (see [5]). Let $H$ be a real Hilbert space, let $C \subset H$ be a nonempty, closed, and convex set. Let $T_{i}$ : $C \rightarrow C$ be uniformly continuous asymptotically $k_{i}$-strict pseudocontractive mappings in the intermediate sense for some $0 \leq k_{i}<1$ with sequences $\left\{\gamma_{n, i}\right\}$ and $\left\{c_{n, i}\right\}$ such that $\lim _{n \rightarrow \infty} \gamma_{n, i}=0$ and $\lim _{n \rightarrow \infty} c_{n, i}=0$ for $i=1,2, \ldots, N$. Let $k=\max \left\{k_{i}: 1 \leq i \leq N\right\}, \gamma_{n}=\max \left\{\gamma_{n, i}: 1 \leq i \leq N\right\}$, and $c_{n}=\max \left\{c_{n, i}: 1 \leq i \leq N\right\}$. Assume that $F:=\bigcap_{n=1}^{N} F\left(T_{i}\right)$ is nonempty and bounded. Let $\left\{\beta_{n}\right\}$ be a sequence in $[0,1]$ such that $0<\delta \leq \beta_{n} \leq 1-k$ for all $n \in N$. Let $\left\{x_{n}\right\}$ be a sequence defined by $x_{0} \in C$ and

$$
\begin{gathered}
y_{n}=\left(1-\beta_{n}\right) x_{n}+\beta_{n} T_{i(n)}^{k(n)} x_{n}, \quad n \geq 1, \\
C_{n}=\left\{z \in C:\left\|y_{n}-z\right\|^{2} \leq\left\|x_{n}-z\right\|^{2}+\theta_{n}\right\}, \\
Q_{n}=\left\{z \in C:\left\langle x_{n}-z, x_{0}-x_{n}\right\rangle \geq 0\right\}, \\
x_{n+1}=P_{C_{n} \cap Q_{n}}\left(x_{0}\right), \quad n \geq 1,
\end{gathered}
$$

where $\theta_{n}=\gamma_{k(n)} \rho_{n}^{2}+c_{k(n)} \rightarrow 0$, as $n \rightarrow \infty$, for $\rho_{n}=$ $\sup \left\{\left\|x_{n}-z\right\|: z \in F\right\}<\infty, n=(h-1) N+i$, where $i=i(n) \in\{1,2, \ldots, N\}, h=h(n) \geq 1$ a positive integer such that $h(n) \rightarrow \infty$, as $n \rightarrow \infty$. Then, $\left\{x_{n}\right\}$ converges strongly to $P_{F}\left(x_{0}\right)$.

But we observe that the iterative algorithms (6) and (7) generate a sequence $\left\{x_{n}\right\}$ by projecting $x_{0}$ onto the intersection of closed convex sets $C_{n}$ and $Q_{n}$ for each $n \geq 1$ which is not easy to compute.

Attempts to remove projection mapping onto the intersection of closed convex sets $C_{n}$ and $Q_{n}$ for each $n \geq 1$ have recently been made. In [6], Zegeye et al. studied the strong convergence of the modified Mann iteration process for the class of asymptotically $k$-strict pseudocontractive mappings 
in the intermediate sense. More precisely, they proved the following theorem.

Theorem ZRS (see [6]). Let $C$ be a nonempty, closed, and convex subset of a real Hilbert space $H$, and let $T: C \rightarrow$ $C$ be a uniformly L-Lipschitzian and asymptotically $k$-strict pseudocontractive mapping in the intermediate sense with sequences $\left\{\gamma_{n}\right\} \subset[0, \infty)$ and $\left\{c_{n}\right\} \subset[0, \infty)$. Assume that the interior of $F(T)$ is nonempty. Let $\left\{x_{n}\right\}$ be a sequence defined by $x_{1}=x \in C$ and

$$
\begin{gathered}
y_{n}=\beta_{n} T^{n} x_{n}+\left(1-\beta_{n}\right) x_{n}, \\
x_{n+1}=\alpha_{n} T^{n} y_{n}+\left(1-\alpha_{n}\right) x_{n}, \quad n \geq 1,
\end{gathered}
$$

where $\left\{\alpha_{n}\right\}$ and $\left\{\beta_{n}\right\}$ satisfy certain conditions. Then, $\left\{x_{n}\right\}$ converges strongly to a fixed point of $T$.

But it is worth to mention that the assumption interior of $F(T)$ is nonempty is severe restriction.

It is our purpose, in this paper, to construct an iteration scheme which converges strongly to a common fixed point of a finite family of uniformly continuous asymptotically $k_{i}$ strict pseudocontractive mappings in the intermediate sense for $i=1,2, \ldots, N$. The projection of $x_{0}$ onto the intersection of closed convex sets $C_{n}$ and $Q_{n}$ for each $n \geq 1$ is not required. Furthermore, the restriction that the interior of $F(T)$ is nonempty is not required. Our theorems improve and unify most of the results that have been proved for this important class of nonlinear mappings.

In order to prove our results, we need the following lemmas.

Lemma 1. Let $H$ be a real Hilbert space. Then, for any given $x$, $y \in H$, the following inequality holds:

$$
\|x+y\|^{2} \leq\|x\|^{2}+2\langle y, x+y\rangle .
$$

Lemma 2 (see [7]). Let $H$ be a real Hilbert space. Then, for all $x, y \in H$ and $\alpha_{i}, \in[0,1]$ for $i=1,2, \ldots, n$ such that $\alpha_{0}+$ $\alpha_{1}+\cdots+\alpha_{n}=1$, the following equality holds:

$$
\begin{aligned}
\| \alpha_{0} x_{0} & +\alpha_{1} x_{1}+\cdots+\alpha_{n} x_{n} \|^{2} \\
& =\sum_{i=0}^{n} \alpha_{i}\left\|x_{i}\right\|^{2}-\sum_{0 \leq i, j \leq n} \alpha_{i} \alpha_{j}\left\|x_{i}-x_{j}\right\|^{2} .
\end{aligned}
$$

Lemma 3 (see [8]). Let $\left\{a_{n}\right\}$ be sequences of real numbers such that there exists a subsequence $\left\{n_{i}\right\}$ of $\{n\}$ such that $a_{n_{i}}<a_{n_{i}+1}$ for all $i \in N$. Then, there exists a nondecreasing sequence $\left\{m_{k}\right\} \subset N$ such that $m_{k} \rightarrow \infty$, and the following properties are satisfied by all (sufficiently large) numbers $k \in N$ :

$$
a_{m_{k}} \leq a_{m_{k}+1}, \quad a_{k} \leq a_{m_{k}+1} .
$$

In fact, $m_{k}=\max \left\{j \leq k: a_{j}<a_{j+1}\right\}$.

Lemma 4 (see [9]). Let $\left\{a_{n}\right\}$ be a sequence of nonnegative real numbers satisfying the following relation:

$$
a_{n+1} \leq\left(1-\alpha_{n}\right) a_{n}+\alpha_{n} \delta_{n}, \quad n \geq n_{0},
$$

where $\left\{\alpha_{n}\right\} \subset(0,1)$ and $\left\{\delta_{n}\right\} \subset R$ satisfying the following conditions: $\lim _{n \rightarrow \infty} \alpha_{n}=0, \sum_{n=1}^{\infty} \alpha_{n}=\infty$ and $\lim \sup _{n \rightarrow \infty} \delta_{n} \leq 0$. Then, $\lim _{n \rightarrow \infty} a_{n}=0$.

Lemma 5 (see [4]). Let $C$ be a nonempty closed convex subset of a Hilbert space $H$, and let $T: C \rightarrow C$ be a continuous asymptotically $k$-strict pseudocontractive mapping in the intermediate sense. Then, $F(T)$ is closed and convex.

Lemma 6 (see [4]). Let $C$ be a nonempty closed convex subset of a Hilbert space $H$, and let $T: C \rightarrow C$ be a uniformly continuous asymptotically $k$-strict pseudocontractive mapping in the intermediate sense. Let $\left\{x_{n}\right\}$ be a sequence in $C$ such that $\left\|x_{n}-T^{n} x_{n}\right\| \rightarrow 0$ and $\left\|x_{n}-x_{n+1}\right\| \rightarrow 0$, as $n \rightarrow \infty$. Then, $\left\|x_{n}-T x_{n}\right\| \rightarrow 0$, as $n \rightarrow \infty$.

Lemma 7 (see [4]). Let $C$ be a nonempty closed convex subset of a Hilbert space $H$, and $T: C \rightarrow C$ be a continuous asymptotically $k$-strict pseudocontractive mapping in the intermediate sense. Then if $\left\{x_{n}\right\}$ is a sequence in $C$ such that $x_{n}$ converges weakly $x \in C$ and $\lim \sup _{m \rightarrow \infty} \limsup _{n \rightarrow \infty} \| x_{n}-$ $T^{m} x_{n} \|=0$, then $(I-T) x=0$.

Lemma 8 (see [10]). Let $C$ be a nonempty closed, convex subset of a Hilbert space $H$ and let $P_{C}$ be the metric projection mapping from $H$ onto $C$. Given $z=P_{C} x$ if and only if $\langle y-$ $z, x-z\rangle \leq 0$, for all $y \in C$.

\section{Main Result}

Theorem 9. Let $C$ be a nonempty, closed and convex subset of a real Hilbert space $H$. Let $T_{i}: C \rightarrow C$ be uniformly continuous asymptotically $k_{i}$-strict pseudocontractive mappings in the intermediate sense for some $0 \leq k_{i}<1$ with sequences $\left\{\gamma_{n, i}\right\}$ and $\left\{c_{n, i}\right\}$, for $i=1,2, \ldots, N$. Assume that $F:=\bigcap_{i=1}^{N} F\left(T_{i}\right)$ is nonempty. Let $\left\{x_{n}\right\}$ be a sequence generated by

$$
\begin{gathered}
x_{0}=w \in C \text { chosen arbitrarily, } \\
y_{n}=\beta_{n, 0} x_{n}+\sum_{i=1}^{N} \beta_{n, i} T_{i}^{n} x_{n}, \\
x_{n+1}=\alpha_{n} w+\left(1-\alpha_{n}\right) y_{n},
\end{gathered}
$$

where $0<\alpha_{n} \leq a_{0}<1$ such that $\lim _{n \rightarrow \infty} \alpha_{n}=0, \sum_{n=1}^{\infty} \alpha_{n}=$ $\infty, \lim _{n \rightarrow \infty}\left[\gamma_{n, i} / \alpha_{n}\right]=0=\lim _{n \rightarrow \infty}\left[c_{n, i} / \alpha_{n}\right]$, and $0<\delta \leq$ $\beta_{n, i} \leq 1-k-\delta<1$ satisfying $\beta_{n, 0}+\beta_{n, 1}+\cdots+\beta_{n, N}=1$ for each $n \geq 1$ and $k:=\max \left\{k_{i}: i=1,2, \ldots, N\right\}$. Then, $\left\{x_{n}\right\}$ converges strongly to an element of $F$.

Proof. Let $x^{*}=P_{F} w$. Let $\gamma_{n}:=\max \left\{\gamma_{n, i}: i=1,2, \ldots, N\right\}$ and $c_{n}:=\max \left\{c_{n, i}: i=1,2, \ldots, N\right\}$. Then, from (13), Lemma 2, 
and asymptotically $k_{i}$-strict pseudocontractiveness of $T_{i}$, for each $i \in\{1,2, \ldots, N\}$, we get that

$$
\begin{aligned}
\| y_{n}-x^{*} & \|^{2} \\
= & \left\|\beta_{n, 0} x_{n}+\sum_{i=1}^{N} \beta_{n, i} T_{i}^{n} x_{n}-x^{*}\right\|^{2} \\
\leq & \beta_{n, 0}\left\|x_{n}-x^{*}\right\|^{2}+\sum_{i=1}^{N} \beta_{n, i}\left\|T_{i}^{n} x_{n}-x^{*}\right\|^{2} \\
& -\sum_{i=1}^{N} \beta_{n, 0} \beta_{n, i}\left\|T_{i}^{n} x_{n}-x_{n}\right\|^{2} \\
\leq & \beta_{n, 0}\left\|x_{n}-x^{*}\right\|^{2}+\left(1-\beta_{n, 0}\right)\left(1+\gamma_{n}\right)\left\|x_{n}-x^{*}\right\|^{2} \\
& +\sum_{i=1}^{N} \beta_{n, i} k\left\|T_{i}^{n} x_{n}-x_{n}\right\|^{2}+\left(1-\beta_{n, 0}\right) c_{n} \\
& -\sum_{i=1}^{N} \beta_{n, 0} \beta_{n, i}\left\|T_{i}^{n} x_{n}-x_{n}\right\|^{2} \\
\leq & \left(1+\gamma_{n}\right)\left\|x_{n}-x^{*}\right\|^{2} \\
\leq & \left(1+\gamma_{n}\right)\left\|x_{n}-x^{*}\right\|^{2}-\delta^{2} \sum_{i=1}^{N}\left\|T_{i}^{n} x_{n}-x_{n}\right\|^{2}+\left(1-\beta_{n, 0}\right) c_{n} \\
& -\sum_{i=1}^{N} \beta_{n, i}(1-k-\delta)\left\|T_{i}^{n} x_{n}-x_{n}\right\|^{2}+\left(1-\beta_{n, 0}\right) c_{n} \\
&
\end{aligned}
$$

$$
\begin{aligned}
\| x_{n+1}- & x^{*} \|^{2} \\
= & \left\|\alpha_{n} w+\left(1-\alpha_{n}\right) y_{n}-x^{*}\right\|^{2} \\
\leq & \alpha_{n}\left\|w-x^{*}\right\|^{2}+\left(1-\alpha_{n}\right)\left\|y_{n}-x^{*}\right\|^{2} \\
\leq & \alpha_{n}\left\|w-x^{*}\right\|^{2}+\left(1-\alpha_{n}\right) \\
& \times\left[\left(1+\gamma_{n}\right)\left\|x_{n}-x^{*}\right\|^{2}-\delta^{2}\right. \\
& \left.\times \sum_{i=1}^{N}\left\|T_{i}^{n} x_{n}-x_{n}\right\|^{2}+\left(1-\beta_{n, 0}\right) c_{n}\right] \\
\leq & \alpha_{n}\left\|w-x^{*}\right\|^{2}+\left(1-\alpha_{n}\right)\left(1+\gamma_{n}\right)\left\|x_{n}-x^{*}\right\|^{2} \\
& -\left(1-\alpha_{n}\right) \delta^{2} \sum_{i=1}^{N}\left\|T_{i}^{n} x_{n}-x_{n}\right\|^{2}+\left(1-\alpha_{n}\right)\left(1-\beta_{n, 0}\right) c_{n} \\
\leq & \alpha_{n}\left[\left\|w-x^{*}\right\|^{2}+1\right]+\left(1-\alpha_{n}(1-\epsilon)\right)\left\|x_{n}-x^{*}\right\|^{2} \\
\leq & \alpha_{n}\left[\left\|w-x^{*}\right\|^{2}+1\right]+\left(1-\alpha_{n}(1-\epsilon)\right)\left\|x_{n}-x^{*}\right\|^{2} \\
& -\left(1-\alpha_{n}\right) \delta^{2} \sum_{i=1}^{N}\left\|T_{i}^{n} x_{n}-x_{n}\right\|^{2}
\end{aligned}
$$

since there exists $N_{0}>0$ such that $\gamma_{n} / \alpha_{n} \leq \epsilon$ and $c_{n} / \alpha_{n} \leq 1$ for all $n \geq N_{0}$ and for some $\epsilon>0$ satisfying $(1-\epsilon) \alpha_{n} \leq 1$. Thus, by induction,

$$
\begin{array}{r}
\left\|x_{n+1}-x^{*}\right\|^{2} \\
\leq \max \left\{(1-\epsilon)^{-1}\left[\left\|w-x^{*}\right\|^{2}+1\right],\left\|x_{0}-x^{*}\right\|^{2}\right\}, \\
\forall n \geq N_{0},
\end{array}
$$

which implies that $\left\{x_{n}\right\}$, and hence $\left\{T_{i}^{n} x_{n}\right\}$ and $\left\{y_{n}\right\}$ are bounded. Moreover, from (13), (14) and Lemma 1, we obtain that

$$
\begin{aligned}
\| x_{n+1}- & x^{*} \|^{2} \\
= & \left\|\alpha_{n}\left(w-x^{*}\right)+\left(1-\alpha_{n}\right)\left(y_{n}-x^{*}\right)\right\|^{2} \\
\leq & \left(1-\alpha_{n}\right)\left\|y_{n}-x^{*}\right\|^{2}+2 \alpha_{n}\left\langle w-x^{*}, x_{n+1}-x^{*}\right\rangle \\
\leq & \left(1-\alpha_{n}\right)\left[\left(1+\gamma_{n}\right)\left\|x_{n}-x^{*}\right\|^{2}-\delta^{2} \sum_{i=1}^{N}\left\|T_{i}^{n} x_{n}-x_{n}\right\|^{2}\right. \\
& \left.+\left(1-\beta_{n, 0}\right) c_{n}\right]+2 \alpha_{n}\left\langle w-x^{*}, x_{n+1}-x^{*}\right\rangle \\
\leq & \left(1-\alpha_{n}\right)\left\|x_{n}-x^{*}\right\|^{2}+\left(1-\alpha_{n}\right) \gamma_{n}\left\|x_{n}-x^{*}\right\|^{2} \\
& -\delta^{2}\left(1-\alpha_{n}\right) \sum_{i=1}^{N}\left\|T_{i}^{n} x_{n}-x_{n}\right\|^{2}+\left(1-\alpha_{n}\right)\left(1-\beta_{n, 0}\right) c_{n} \\
& +2 \alpha_{n}\left\langle w-x^{*}, x_{n+1}-x^{*}\right\rangle \\
\leq & \left(1-\alpha_{n}\right)\left\|x_{n}-x^{*}\right\|^{2}+2 \alpha_{n}\left\langle w-x^{*}, x_{n+1}-x^{*}\right\rangle \\
& +\left(\gamma_{n}+c_{n}\right) M \\
& +\left(\gamma_{n}+c_{n}\right) M-\delta_{n}^{2}\left(1-a_{0}\right) \sum_{i=1}^{N}\left\|T_{i}^{n} x_{n}-x_{n}\right\|^{2} \\
& (18) \\
& \\
& \\
& \\
& \\
&
\end{aligned}
$$

for some $M>0$ and for all $n \in N$.

Now, following the method of proof of Lemma 3.2 of Maingé [8], we consider two cases.

Case 1. Suppose that there exists $n_{0} \in N$ such that $\left\{\left\|x_{n}-x^{*}\right\|\right\}$ is nonincreasing for all $n \geq n_{0}$. In this situation, $\left.\left\{\left\|x_{n}-x^{*}\right\|\right)\right\}$ is convergent. Then, from (17), we have that

$$
x_{n}-T_{i}^{n} x_{n} \longrightarrow 0, \quad \text { as } n \longrightarrow \infty \text {, }
$$

for $i=1,2, \ldots, N$. Moreover, from (13) and (19) and the fact that $\alpha_{n} \rightarrow 0$, we get that

$$
\begin{gathered}
\left\|y_{n}-x_{n}\right\| \leq \sum_{i=1}^{N} \beta_{n, i}\left\|T_{i}^{n} x_{n}-x_{n}\right\| \longrightarrow 0, \\
x_{n+1}-y_{n}=\alpha_{n}\left(w-y_{n}\right) \longrightarrow 0,
\end{gathered}
$$


as $n \rightarrow \infty$, and hence

$$
\left\|x_{n+1}-x_{n}\right\| \longrightarrow 0, \quad \text { as } n \longrightarrow \infty \text {. }
$$

Furthermore, from (19), (21), and Lemma 6, we obtain that

$$
x_{n}-T_{i} x_{n} \longrightarrow 0, \quad \text { as } n \longrightarrow \infty .
$$

Let $\left\{x_{n_{k}+1}\right\}$ be a subsequence of $\left\{x_{n+1}\right\}$ such that $\limsup _{n \rightarrow \infty}\left\langle w-x^{*}, x_{n+1}-x^{*}\right\rangle=\lim _{k \rightarrow \infty}\left\langle w-x^{*}, x_{n_{k}+1}-x^{*}\right\rangle$ and $\left\{x_{n_{k}+1}\right\}$ converges weakly to $v$. Then, from (21), we also get that $\left\{x_{n_{k}}\right\}$ converges weakly to $v$. Moreover, since $T_{i}$ is uniformly continuous and $\left\|x_{n}-T_{i} x_{n}\right\| \rightarrow 0$, for all $i \in\{1,2, \ldots, N\}$, we get that $\left\|x_{n}-T_{i}^{m} x_{n}\right\| \rightarrow 0$, as $n \rightarrow \infty$, for all $m \in N$. Therefore, by Lemma 7, we obtain that $v \in \bigcap_{i=1}^{N} F\left(T_{i}\right)$. Now, from Lemma 8, we have that

$$
\limsup _{n \rightarrow \infty}\left\langle w-x^{*}, x_{n+1}-x^{*}\right\rangle=\left\langle w-x^{*}, v-x^{*}\right\rangle \leq 0 .
$$

Then, from (18), (23), and Lemma 4 , we obtain that $\| x_{n}-$ $x^{*} \| \rightarrow 0$, as $n \rightarrow \infty$. Consequently, $x_{n} \rightarrow x^{*}$.

Case 2. Suppose that there exists a subsequence $\left\{n_{i}\right\}$ of $\{n\}$ such that

$$
\left\|x_{n_{i}}-x^{*}\right\|<\left\|x_{n_{i}+1}-x^{*}\right\|
$$

for all $i \in N$. Then, by Lemma 3, there exist a nondecreasing sequence $\left\{m_{k}\right\} \subset N$ such that $m_{k} \rightarrow \infty$,

$$
\left\|x_{m_{k}}-x^{*}\right\| \leq\left\|x_{m_{k}+1}-x^{*}\right\|
$$

and $\left\|x_{k}-x^{*}\right\| \leq\left\|x_{m_{k}+1}-x^{*}\right\|$, for all $k \in N$. Then, from (17) and the fact that $\alpha_{n} \rightarrow 0$, we have

$$
\begin{aligned}
\delta^{2}(1- & \left.a_{0}\right) \sum_{i=1}^{N}\left\|x_{m_{k}}-T_{i}^{m_{k}} x_{m_{k}}\right\|^{2} \\
\leq & \left\|x_{m_{k}}-x^{*}\right\|^{2}-\left\|x_{m_{k}+1}-x^{*}\right\|^{2} \\
& +\alpha_{m_{k}}\left\|x_{m_{k}}-x^{*}\right\|^{2}+2 \alpha_{m_{k}}\left\langle w-x^{*}, x_{m_{k}+1}-x^{*}\right\rangle \\
& +\left(\gamma_{m_{k}}+c_{m_{k}}\right) M \longrightarrow 0, \text { as } k \longrightarrow \infty .
\end{aligned}
$$

Then, we get that $x_{m_{k}}-T_{i}^{m_{k}} x_{m_{k}} \rightarrow 0$, as $n \rightarrow \infty$, for each $i=1,2, \ldots, N$. Thus, as in Case 1 , we obtain that $x_{m_{k}}-y_{m_{k}} \rightarrow$ 0 and $x_{m_{k}+1}-x_{m_{k}} \rightarrow 0$, as $k \rightarrow \infty$ and

$$
\limsup _{k \rightarrow \infty}\left\langle w-x^{*}, x_{m_{k}+1}-x^{*}\right\rangle \leq 0 .
$$

Now, from (18), we have that

$$
\begin{aligned}
\| x_{m_{k}+1} & -x^{*} \|^{2} \\
\leq & \left(1-\alpha_{m_{k}}\right)\left\|x_{m_{k}}-x^{*}\right\| \\
& +2 \alpha_{m_{k}}\left\langle w-x^{*}, x_{m_{k}+1}-x^{*}\right\rangle+\left(\gamma_{m_{k}}+c_{m_{k}}\right) M .
\end{aligned}
$$

This implies that

$$
\begin{aligned}
\alpha_{m_{k}}\left\|x_{m_{k}}-x^{*}\right\|^{2} & \\
\leq & \left\|x_{m_{k}}-x^{*}\right\|^{2}-\left\|x_{m_{k}+1}-x^{*}\right\|^{2} \\
& +2 \alpha_{m_{k}}\left\langle w-x^{*}, x_{m_{k}+1}-x^{*}\right\rangle+\left(\gamma_{m_{k}}+c_{m_{k}}\right) M .
\end{aligned}
$$

Then, using (25), inequality (29) implies that

$$
\begin{aligned}
& \alpha_{m_{k}}\left\|x_{m_{k}}-x^{*}\right\|^{2} \\
& \quad \leq 2 \alpha_{m_{k}}\left\langle w-x^{*}, x_{m_{k}+1}-x^{*}\right\rangle+\left(\gamma_{m_{k}}+c_{m_{k}}\right) M .
\end{aligned}
$$

In particular, since $\alpha_{m_{k}}>0$, we get

$$
\left\|x_{m_{k}}-x^{*}\right\|^{2} \leq 2\left\langle w-x^{*}, x_{m_{k}+1}-x^{*}\right\rangle+\frac{\gamma_{m_{k}}+c_{m_{k}}}{\alpha_{m_{k}}} .
$$

Furthermore, using (27) and the fact that $\left(\gamma_{m_{k}}+c_{m_{k}}\right) / \alpha_{m_{k}} \rightarrow$ 0 , we obtain that $\left\|x_{m_{k}}-x^{*}\right\| \rightarrow 0$, as $k \rightarrow \infty$. This together with (28) give $\left\|x_{m_{k}+1}-x^{*}\right\| \rightarrow 0$, as $k \rightarrow \infty$. But $\left\|x_{k}-x^{*}\right\| \leq$ $\left\|x_{m_{k}+1}-x^{*}\right\|$ for all $k \in N$. Thus we obtain that $x_{k} \rightarrow x^{*}$. Therefore, from the above two cases, we can conclude that $\left\{x_{n}\right\}$ converges strongly to an element of $F$, and the proof is complete.

If in Theorem 9, we assume that $N=1$, then we get the following corollary.

Corollary 10. Let $C$ be a nonempty, closed, and convex subset of a real Hilbert space $H$. Let $T: C \rightarrow C$ be a uniformly continuous asymptotically $k$-strict pseudocontractive mapping in the intermediate sense for some $0 \leq k<1$ with sequences $\left\{\gamma_{n}\right\}$ and $\left\{c_{n}\right\}$. Assume that $F:=F(T)$ is nonempty. Let $\left\{x_{n}\right\}$ be a sequence generated by

$$
\begin{gathered}
x_{0}=w \in C \text { chosen arbitrarily, } \\
y_{n}=\beta_{n} x_{n}+\left(1-\beta_{n}\right) T^{n} x_{n}, \\
x_{n+1}=\alpha_{n} w+\left(1-\alpha_{n}\right) y_{n},
\end{gathered}
$$

where $0<\alpha_{n} \leq a_{0}<1$ such that $\lim _{n \rightarrow \infty} \alpha_{n}=0, \sum_{n=1}^{\infty} \alpha_{n}=$ $\infty, \lim _{n \rightarrow \infty}\left[\gamma_{n} / \alpha_{n}\right]=0=\lim _{n \rightarrow \infty}\left[c_{n} / \alpha_{n}\right]$, and $0<\delta \leq \beta_{n} \leq$ $1-k-\delta<1$ for each $n \geq 1$. Then, $\left\{x_{n}\right\}$ converges strongly to an element of $F$.

If in Theorem 9, we assume that each $T_{i}$ is asymptotically $k_{i}$-strict pseudocontractive mapping, then we get the following corollary.

Corollary 11. Let $C$ be a nonempty, closed, and convex subset of a real Hilbert space $H$. Let $T_{i}: C \rightarrow C$ be asymptotically $k_{i}$-strict pseudocontractive mappings for some $0 \leq k_{i}<1$ 
with sequences $\left\{\gamma_{n, i}\right\}$, for $i=1,2, \ldots, N$. Assume that $F:=$ $\bigcap_{i=1}^{N} F\left(T_{i}\right)$ is nonempty. Let $\left\{x_{n}\right\}$ be a sequence generated by

$$
\begin{gathered}
x_{0}=w \in C \text { chosen arbitrarily, } \\
y_{n}=\beta_{n, 0} x_{n}+\sum_{i=1}^{N} \beta_{n, i} T_{i}^{n} x_{n}, \\
x_{n+1}=\alpha_{n} w+\left(1-\alpha_{n}\right) y_{n},
\end{gathered}
$$

where $0<\alpha_{n} \leq a_{0}<1$ such that $\lim _{n \rightarrow \infty} \alpha_{n}=0, \sum_{n=1}^{\infty} \alpha_{n}=$ $\infty, \lim _{n \rightarrow \infty}\left[\gamma_{n, i} / \alpha_{n}\right]=0$, and $0<\delta \leq \beta_{n, i} \leq 1-k-\delta<1$ satisfying $\beta_{n, 0}+\beta_{n, 1}+\cdots+\beta_{n, N}=1$ for each $n \geq 1$ and $k:=$ $\max \left\{k_{i}: i=1,2, \ldots, N\right\}$. Then, $\left\{x_{n}\right\}$ converges strongly to an element of $F$.

Proof. Since every asymptotically $k_{i}$-strict pseudocontractive mapping is uniformly continuous and asymptotically $k_{i}$-strict pseudocontractive mapping in the intermediate sense with $c_{n, i} \equiv 0$, for all $n \geq 1$ and each $i=1,2, \ldots, N$, the conclusion follows from Theorem 9 .

If in Theorem 9, we assume that each $T_{i}$ is asymptotically nonexpansive in the intermediate sense we obtain the following corollary.

Corollary 12. Let $C$ be a nonempty, closed, and convex subset of a real Hilbert space $H$. Let $T_{i}: C \rightarrow C$ be uniformly continuous asymptotically nonexpansive mappings in the intermediate sense with sequences $\left\{\gamma_{n, i}\right\}$ and $\left\{c_{n, i}\right\}$, for $i=1,2, \ldots, N$. Assume that $F:=\bigcap_{i=1}^{N} F\left(T_{i}\right)$ is nonempty. Let $\left\{x_{n}\right\}$ be a sequence generated by

$$
\begin{gathered}
x_{0}=w \in C \text { chosen arbitrarily, } \\
y_{n}=\beta_{n, 0} x_{n}+\sum_{i=1}^{N} \beta_{n, i} T_{i}^{n} x_{n}, \\
x_{n+1}=\alpha_{n} w+\left(1-\alpha_{n}\right) y_{n},
\end{gathered}
$$

where $0<\alpha_{n} \leq a_{0}<1$ such that $\lim _{n \rightarrow \infty} \alpha_{n}=0, \sum_{n=1}^{\infty} \alpha_{n}=$ $\infty, \lim _{n \rightarrow \infty}\left[\gamma_{n, i} / \alpha_{n}\right]=0=\lim _{n \rightarrow \infty}\left[c_{n, i} / \alpha_{n}\right]$, and $0<\delta \leq$ $\beta_{n, i} \leq 1-\delta<1$ satisfying $\beta_{n, 0}+\beta_{n, 1}+\cdots+\beta_{n, N}=1$ for each $n \geq 1$. Then, $\left\{x_{n}\right\}$ converges strongly to an element of $F$.

Proof. Since every asymptotically nonexpansive mapping in the intermediate sense is asymptotically $k_{i}$-strict pseudocontractive mapping in the intermediate sense with $k_{i}=0$, for each $i=1,2, \ldots, N$, the conclusion follows from Theorem 9 .

If in Theorem 9, we assume that each $T_{i}$ is asymptotically nonexpansive, we obtain the following corollary.

Corollary 13. Let $C$ be a nonempty, closed, and convex subset of a real Hilbert space $H$. Let $T_{i}: C \rightarrow C$ be asymptotically nonexpansive mappings with sequences $\left\{\gamma_{n, i}\right\}$, for $i=1,2, \ldots, N$. Assume that $F:=\bigcap_{i=1}^{N} F\left(T_{i}\right)$ is nonempty. Let $\left\{x_{n}\right\}$ be a sequence generated by

$$
\begin{gathered}
x_{0}=w \in C \text { chosen arbitrarily, } \\
y_{n}=\beta_{n, 0} x_{n}+\sum_{i=1}^{N} \beta_{n, i} T_{i}^{n} x_{n}, \\
x_{n+1}=\alpha_{n} w+\left(1-\alpha_{n}\right) y_{n},
\end{gathered}
$$

where $0<\alpha_{n} \leq a_{0}<1$ such that $\lim _{n \rightarrow \infty} \alpha_{n}=0, \sum_{n=1}^{\infty} \alpha_{n}=$ $\infty, \lim _{n \rightarrow \infty}\left[\gamma_{n, i} / \alpha_{n}\right]=0$, and $0<\delta \leq \beta_{n, i} \leq 1-\delta<1$ satisfying $\beta_{n, 0}+\beta_{n, 1}+\cdots+\beta_{n, N}=1$ for each $n \geq 1$. Then, $\left\{x_{n}\right\}$ converges strongly to an element of $F$.

Proof. Since every asymptotically nonexpansive mapping is uniformly continuous and asymptotically $k_{i}$-strict pseudocontractive mapping with $k_{i}=0$ and $c_{n, i}=0$, for all $n \geq 1$ and $i=1,2, \ldots, N$, the conclusion follows from Theorem 9 .

Remark 14. Our results extend and unify most of the results that have been proved for this important class of nonlinear mappings. In particular, Theorem 9 extends Theorem SXY1, SXY2, HC, and Theorem ZRS in the sense that our convergence is either strong, does not require computation of closed convex sets $C_{n}$ and $Q_{n}$ for each $n \geq 1$, or does not require the assumption that interior of set of fixed points is nonempty.

Remark 15. We also remark that Corollary 11 is more general than Theorem 3.1 of Kim and $\mathrm{Xu}$ [3] and Corollary 13 is more general than Theorem 2.2 of $\mathrm{Kim}$ and $\mathrm{Xu}$ [11] in the sense that our convergence is either strong, does not require computation of closed convex sets $C_{n}$ and $Q_{n}$ for each $n \geq 1$, or does not require the assumption that interior of set of fixed points is nonempty.

\section{Acknowledgment}

The research of $\mathrm{N}$. Shahzad was partially supported by the Deanship of Scientific Research (DSR), King Abdulaziz University, Jeddah, Saudi Arabia.

\section{References}

[1] Q. H. Liu, "Convergence theorems of the sequence of iterates for asymptotically demicontractive and hemi-contractive mappings," Nonlinear Analysis, vol. 26, pp. 1838-1842, 1996.

[2] Y. X. Tian, S.-S. Chang, J. Huang, X. Wang, and J. K. Kim, "Implicit iteration process for common fixed points of strictly asymptotically pseudocontractive mappings in Banach spaces," Fixed Point Theory and Applications, vol. 2008, Article ID 324575, 12 pages, 2008.

[3] T.-H. Kim and H.-K. Xu, "Convergence of the modified Mann's iteration method for asymptotically strict pseudo-contractions," Nonlinear Analysis, vol. 68, no. 9, pp. 2828-2836, 2008.

[4] D. R. Sahu, H.-K. Xu, and J.-C. Yao, "Asymptotically strict pseudocontractive mappings in the intermediate sense," Nonlinear Analysis, vol. 70, no. 10, pp. 3502-3511, 2009. 
[5] C. S. Hu and G. Cai, "Convergence theorems for equilibrium problems and fixed point problems of a finite family of asymptotically $k$-strictly pseudocontractive mappings in the intermediate sense," Computers \& Mathematics with Applications, vol. 61, no. 1, pp. 79-93, 2011.

[6] H. Zegeye, M. Robdera, and B. Choudhary, "Convergence theorems for asymptotically pseudocontractive mappings in the intermediate sense," Computers \& Mathematics with Applications, vol. 62, no. 1, pp. 326-332, 2011.

[7] H. Zegeye and N. Shahzad, "Convergence of Manns type iteration method for generalized asymptotically nonexpansive mappings," Computers and Mathematics With Applications, vol. 62, no. 11, pp. 4007-4014, 2011.

[8] P.-E. Maingé, "Strong convergence of projected subgradient methods for nonsmooth and nonstrictly convex minimization," Set-Valued Analysis, vol. 16, no. 7-8, pp. 899-912, 2008.

[9] J. G. O'Hara, P. Pillay, and H.-K. Xu, "Iterative approaches to convex feasibility problems in Banach spaces," Nonlinear Analysis, vol. 64, no. 9, pp. 2022-2042, 2006.

[10] W. Takahashi, Nonlinear Functional Analysis-Fixed Point Theory and Applications, Yokohama Publishers, Yokohama, Japan, 2000.

[11] T.-H. Kim and H.-K. Xu, "Strong convergence of modified Mann iterations for asymptotically nonexpansive mappings and semigroups," Nonlinear Analysis, vol. 64, no. 5, pp. 1140-1152, 2006. 


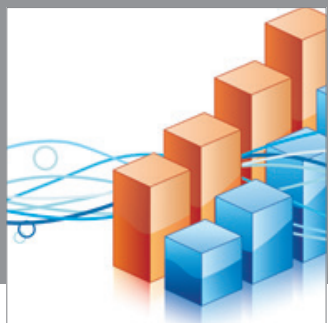

Advances in

Operations Research

mansans

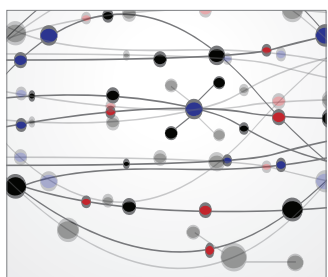

The Scientific World Journal
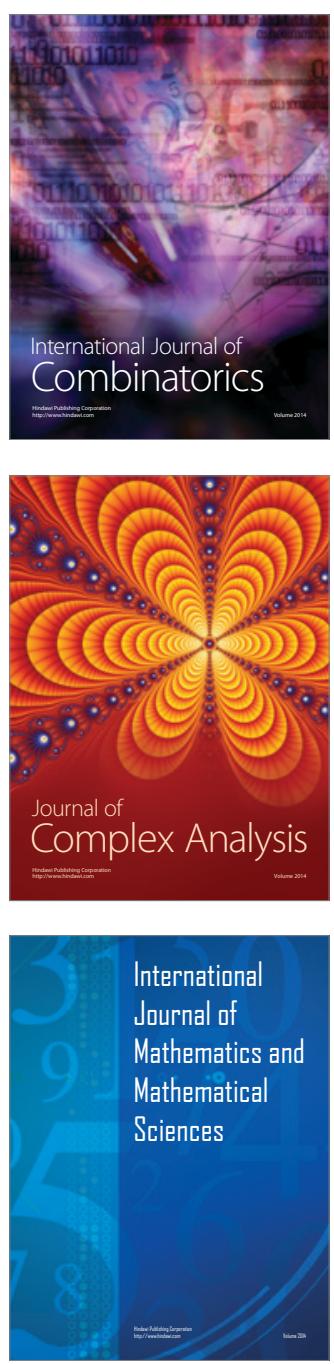
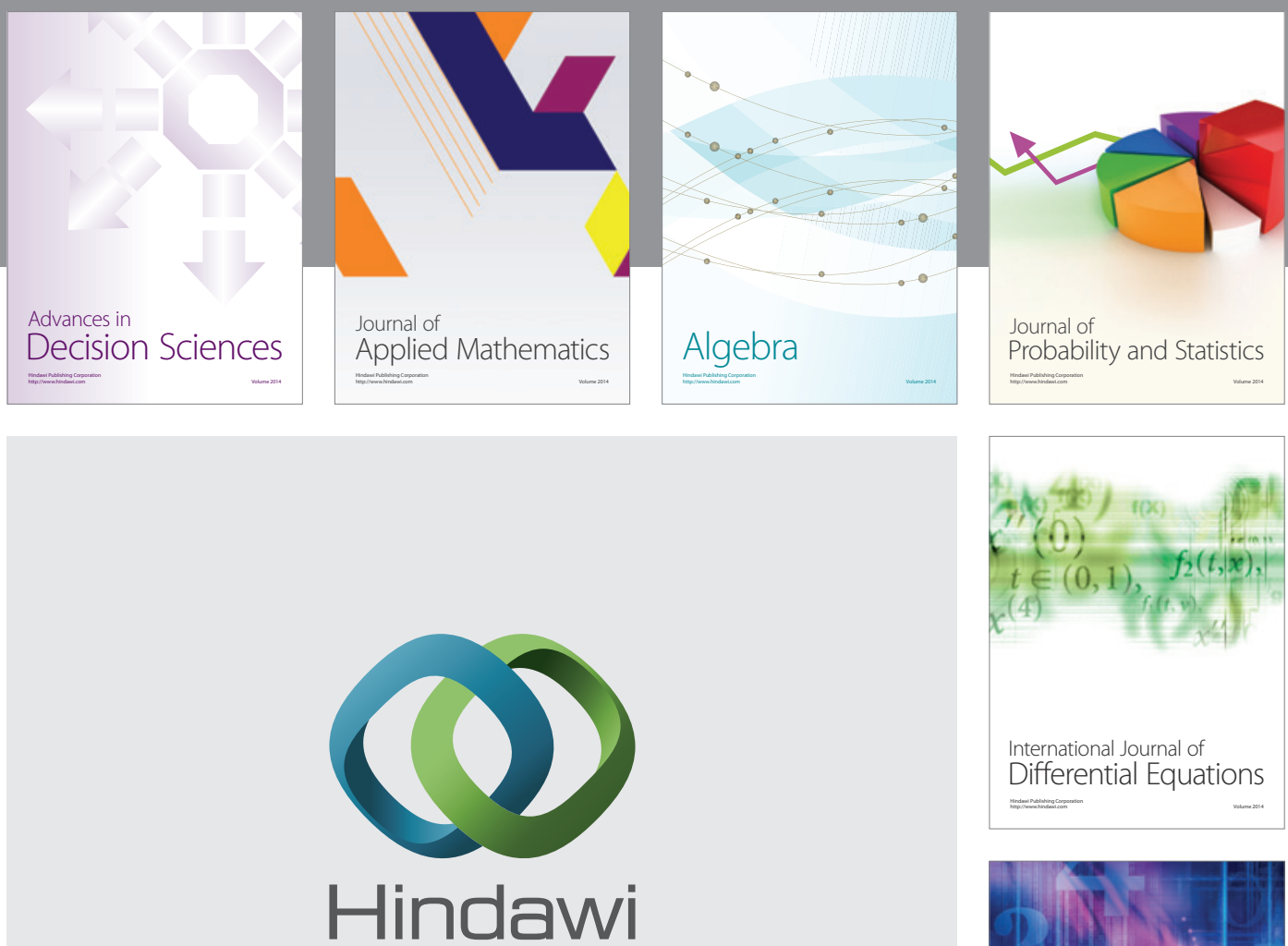

Submit your manuscripts at http://www.hindawi.com
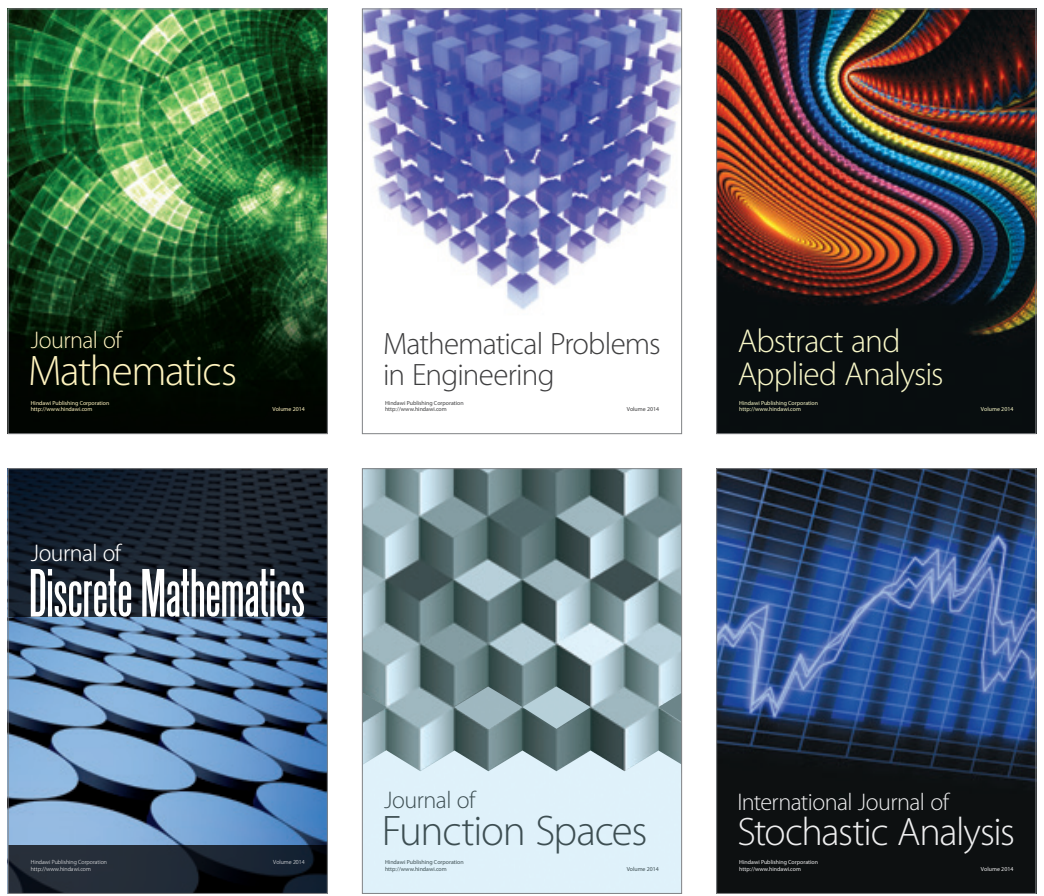

Journal of

Function Spaces

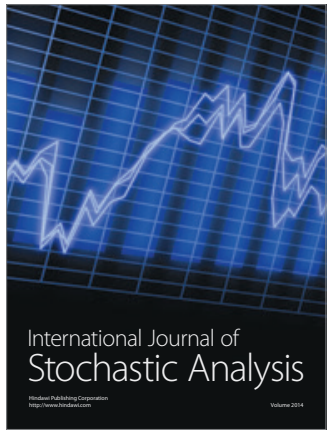

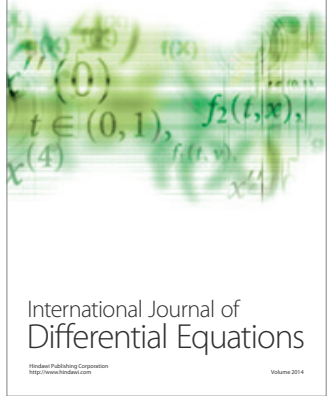
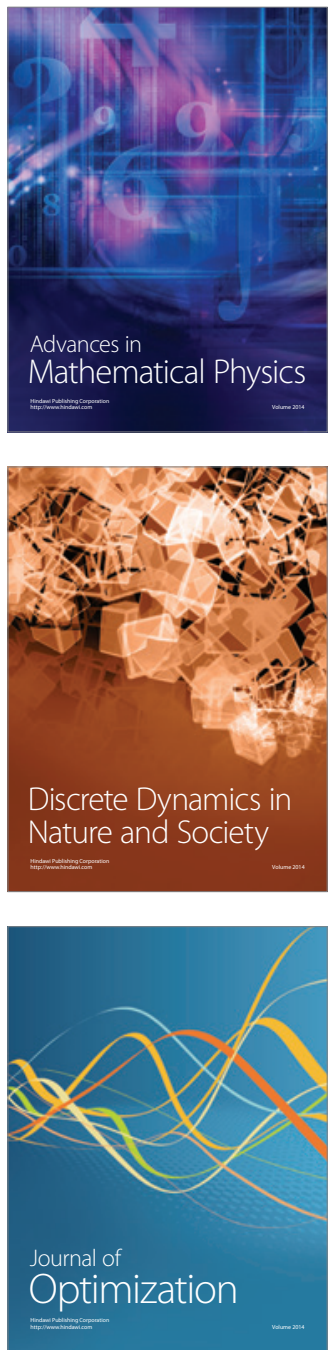